A R T I G O

\title{
PODE A HISTÓRIA ORAL AJUDAR A ADIAR O FIM DO MUNDO? COVID-19: TEMPO, TESTEMUNHO E HISTÓRIA
}

Can oral history help to postpone the end of the world? COVID-19: time, testimony and history

¿Puede la historia oral ayudar a posponer el fin del mundo? COVID-19: tiempo, testimonio e historia

\author{
CARla Simone RODEGHERO ${ }^{\text {* }}$ \\ RODRIGO DE AZEVEDO WEIMER ${ }^{\mathrm{II**}}$
}

https://doi.org/10.1590/S2178-149420210303

Universidade Federal do Rio Grande do Sul - Porto Alegre (RS), Brasil.

*Doutora em História pela Universidade Federal do Rio Grande do Sul (carla.simone@ufrgs.br)

(D) https://orcid.org/0000-0002-2669-726X

"Arquivo Público do Estado do Rio Grande do Sul, Universidade Federal do Rio Grande do Sul - Porto Alegre (RS), Brasil.

**Doutor em História pela Universidade Federal Fluminense (rod_weimer@hotmail.com)

(D) https://orcid.org/0000-0003-1536-6243

Artigo recebido em 27 de abril de 2021 e aprovado para publicação em 14 de julho de 2021. 


\title{
RESUMO
}

0 texto analisa 16 entrevistas realizadas entre 2020 e 2021, em um projeto de história oral sobre o cotidiano da COVID-19, explorando como as noç̃̃es de tempo, testemunho e história são acionadas no contexto pandêmico. Foi dada atenção às narrativas de gestores públicos estaduais e estudantes de graduação de baixa renda sobre duas questões: "você teria algo a acrescentar que não foi perguntado?" e "por que você aceitou fazer parte da pesquisa?". Esses questionamentos deram acesso a testemunhos sobre o ato de testemunhar, possibilitando reflexões sobre a história como vivência e como processo de construção do conhecimento.

PALAVRAS-CHAVE: Testemunho do Testemunho; Tempo; História; COVID-19; Ciência; História Oral.

\begin{abstract}
This article analyzes 16 interviews carried out between 2020 and 2021, in an oral history project on the daily life of COVID-19, exploring how the notions of time, testimony and history are triggered in the pandemic context. Attention was paid to the narratives of state public managers and low-income undergraduate students on two questions: "Would you have anything to add that was not asked?" and "Why did you accept to be part of the research?". These questions gave access to testimonies on the act of witnessing, allowing reflections on history as an experience and as a process of knowledge construction.
\end{abstract}

KEYWORDS: Testimony of the Testimony; Time; History; COVID-19; Science; Oral History.

\section{RESUMEN}

El texto analiza dieciséis entrevistas realizadas entre 2020 y 2021 en un proyecto de historia oral sobre la vida cotidiana de COVID-19, explorando cómo se desencadenan las nociones de tiempo, testimonio e historia en el contexto de la pandemia. Se prestó atención a las narrativas de los administradores públicos estatales y los estudiantes de pregrado de bajos ingresos sobre dos preguntas: " ¿Tiene algo que agregar que no se haya preguntado?" y "¿Por qué aceptó formar parte de la investigación?". Estas preguntas dieron acceso a testimonios sobre el acto de testificar, posibilitando reflexiones sobre la historia como experiencia y como proceso de construcción del conocimiento.

PALABRAS CLAVE: Testimonio de Testimonio; Tiempo; Historia; COVID-19; Ciencia; Historia Oral. 
A minha provocação sobre adiar o fim do mundo é exatamente sempre poder contar mais uma história. Se pudermos fazer isso, estaremos adiando o fim.

(Krenak, 2019: 13).

A AIDS é uma das questões que nos defronta com a nossa incapacidade, enquanto intelectuais críticos, de produzir efeitos reais no mundo em que vivemos [...] Diante da urgência das pessoas que estão morrendo, qual, em nome de Deus, é o propósito dos estudos culturais?

(Hall, 2003: 213).

$E^{n}$ m artigo de 1992, Stuart Hall confessava seu espanto diante da impotência em intervir no mundo de forma a, de alguma maneira, minimizar a mortandade causada pela pandemia de AIDS. Indagava-se, assim, sobre os propósitos de seus estudos, quando tantas pessoas eram abatidas. Três décadas após, vivemos nova pandemia, provocada por novo vírus, e novamente nos questionamos sobre nossos limites diante da tragédia que já vitimou, à ocasião de escrita deste texto, mais de 500 mil pessoas em nosso país. 0 paralelo é inevitável e os dilemas éticos são similares. Essas inquietações não podem ser paralisantes, mas devem nos provocar, como sugeriu Ailton Krenak, a "contar mais uma história"; devem nos mobilizar para, como historiadores/as, fazermos o que sabemos fazer de melhor: "lembrar o que os outros esquecem" (Hobsbawm, 1996: 13). Inspirado por essas reflexões, o presente artigo apresenta o projeto Documentando a Experiência da COVID-19 no Rio Grande do Sul e explora um conjunto de 16 entrevistas de história oral conduzidas pelas equipes do Arquivo Público do Estado do Rio Grande do Sul (APERS) e da Universidade Federal do Rio Grande do Sul (UFRGS) entre 2020 e 2021. Serão enfocadas as narrativas que se referem à importância do testemunho, da ciência e do conhecimento histórico no contexto pandêmico.

\section{FAZER HISTÓRIA ORAL DURANTE A PANDEMIA}

$\mathrm{N}$

o momento vivido, o presente se impôs como temporalidade dominante, projetando-se sobre o futuro e sobre o passado (Hartog, 2013). Esse perene presente oferece grandes desafios para o ofício do/a historiador/a. 0 imediato mui rapidamente torna-se pretérito, e, assim, as batalhas pela memória deslocam-se para "hoje". Segundo Hartog (2020), vivemos, com a pandemia, um tempo de urgências, que, onipresentes, são difíceis de hierarquizar. A cada um/a de nós é dado o dever de "habitar" o tempo do confinamento, "preenchê-lo", dando algum sentido à nova ordem temporal, mas, de alguma maneira, articulando-a à possibilidade de um tempo coletivo. É como se nossas vidas tivessem entrado em suspensão, prolongando-se em um presente interminável e angustiante. 0 "passado que não passa" 
transforma-se em um "presente que não passa" — até mesmo nas nossas lidas cotidianas —, e o "dever de memória" também assim o faz.

Se, outrora, havia um revisionismo em relação às tragédias do passado (Vidal-Naquet, 1988), assistimos, no presente, um negacionismo quanto à gravidade da crise sanitária, quanto aos conhecimentos científicos para combatê-la e até mesmo quanto ao real número de mortes. As disputas pela memória não ocorrem retrospectivamente, mas agora, em tempo real, na velocidade das redes sociais, e é agora que o/a historiador/a deve travar as justas batalhas por uma memória que possa dar conta do horror. Nesse presente angustiante, há uma saturação de informações e todos/as se sentem sufocados por elas, o que pode ser caracterizado como infodemia, palavra usada pela primeira vez em 2003, durante a epidemia de Síndrome Respiratória Aguda (SARS). 0 termo se refere a "notícias que misturam medo, especulação e rumores, e que são amplificadas pelas novas tecnologias da informação, afetando a política, a economia e até mesmo a segurança dos países" (Pereira, Marques e Araújo, 2020: 277).

Walter Benjamin observava haver, na modernidade, uma substituição do relato pela informação. Para o filósofo, isso acarretaria uma "redução da experiência", em que se destaca a narrativa, "uma das mais antigas formas de comunicação". A diferença é que a informação pretende transmitir acontecimentos em pura objetividade, ao passo que, no relato, ela é indissociável da narrativa; está integrada à vida do contador de histórias, que a passa como experiência (Benjamin, 2015: 109). Segundo Benjamin, essas informações podem chegar como "choques", isto é, estímulos traumatizantes, diante dos quais a psiquê pode não ter barreiras protetoras. No entanto, os corpos habituam-se aos choques, assimilando seus efeitos traumáticos (Benjamin, 2015: 112-114). Indagamo-nos sobre o que pensaria o autor da infodemia atual, quando somos inundados, muitas vezes ao dia, por terabytes de choques. Diante da saturação, muitas pessoas optam simplesmente por alhear-se dos noticiários, ainda que as notícias, invariavelmente, sub-repticiamente, se imponham por outras fontes. Os "choques" são diários, intensos, incessantes, imediatos, no ritmo das redes sociais e aplicativos de mensagens instantâneas.

Sobre esse cenário, Hartog argumenta:

Hoje se trata, sobretudo, da perturbação no presentismo. Denuncia-se seu curto prazo e considera-se a extensão dos danos que ele gerou. Isso não impede que, no mesmo instante, a extensão do digital, sob suas múltiplas declinações, em que a unidade de conta é o nano-segundo, incite ou obrigue os indivíduos e as instituições a viverem cada vez mais sob o regime do imediatismo (Hartog, 2020: 52-53).

Em uma perspectiva próxima, a categoria atualismo, desenvolvida por Araújo e Pereira (2019) e retomada em obra sobre a COVID-19 (Pereira, Marques e Araújo, 2020: 280), 
dá conta de importantes aspectos da experiência que vivemos hoje. Estamos imersos/as em um "contexto de mutação da técnica", no qual "o futuro tende a deixar de ser um espaço de esperança de transformação, para se tornar uma cópia atualizada e, por isso mesmo, supostamente melhorada do presente". A percepção "de que a realidade se reproduz automaticamente" faz parte dessa realidade, e, de acordo com Pereira, Marques e Araújo (2020: 281), cria a sensação "de que a ação não vale a pena, não é possível ou necessária".

0 imediato, a aceleração, mesclam-se em um tedioso tempo pandêmico que não passa. Segundo Rodrigo Turin (s.d.), o tempo de respiração e desaceleração tornam-se bens de mercado inacessíveis a todos. Tragicamente, o "choque" de mais de meio milhão de mortos — apenas no Brasil — é naturalizado. Ou, então, se evita encará-lo para tornar suportáveis as vivências mais ou menos precárias e insulares. Quando o que vivemos é dificilmente narrável, identificamos um desejo por narrar e por produzir narrativas, para além do mar de informações, o que tem nos instigado a ocupar um lugar de escuta. Antes de nos dedicarmos à recomposição do passado, o desafio que o presente oferece é a contribuição para o registro da barbárie que nos assola. A questão que fica é: como nós, profissionais, seremos capazes de ir além do espanto que abismou Hall? Até que ponto o "contar uma história" sugerido por Krenak pode ser incorporado ao nosso fazer historiador? Para nós, a melhor saída pareceu ser a aparentemente modesta tarefa de documentar a excepcionalidade do momento.

Em texto publicado na revista Nature, Hetan Shah (2021) assinalou a importância das humanidades no combate à pandemia. Segundo o autor, epidemias são fenômenos biológicos e sociais. As análises qualitativas das ciências humanas e sociais ajudam a avaliar os impactos sociais e o comportamento humano no que diz respeito às políticas contra-epidêmicas. Com preocupações similares, e julgando haver um dever de ofício para com o porvir - e com o presente - concebemos e coordenamos o Projeto Documentando a Experiência da COVID-19 no Rio Grande do Sul, junto à colega Clarissa Sommer Alves, historiadora do Arquivo Público do Estado do Rio Grande do Sul. Participam do projeto 14 instituições gaúchas, comprometidas com a aplicação de um questionário abrangente e com a realização de entrevistas de história oral'.

Alessandro Portelli (2016:10) apresenta a história oral como um trabalho histórico no qual "questões ligadas à memória, narrativa, subjetividade e diálogo moldam a própria agenda do historiador". 0 autor caracteriza a história oral como "a arte da escuta, uma arte baseada num conjunto de relações": entre entrevistados e entrevistadores, entre o tempo do narrado e o tempo da narrativa, "entre a oralidade da fonte e a escrita do historiador" (Portelli, 2016:12). Quando pudermos avaliar os empreendimentos de história oral sobre a pandemia levados adiante enquanto ela nos assola, será necessário refletir sobre a caracte- 
rização proposta: estamos experimentando uma mescla do tempo do narrado e do tempo da narrativa, um encolhimento do espaço público em prol do privado, o compartilhamento de experiências entre entrevistadores/as e entrevistados/as. A necessidade de falar e de registrar se coloca como imperativo para todos/as, inclusive nós.

Com base nas reflexões apresentadas e a partir da exploração de um conjunto de entrevistas, objetivamos discutir percepções sobre o tempo pandêmico e, no seio delas, o lugar da ciência, do conhecimento histórico e da história oral.

Voltando à apresentação do projeto Documentando..., acrescentamos que cada instituição envolvida encarregou-se de entrevistar pessoas pertencentes a determinado segmento da sociedade sul-rio-grandense. Espera-se que o conjunto das entrevistas constitua um mosaico de vivências pandêmicas. Os grupos contemplados por nossas instituições, UFRGS e APERS, foram, respectivamente, estudantes de graduação de baixa renda e gestores/as públicos/as da administração estadual. Esses dois grupos permitem verificar extremos sociais, distantes em termos de capital econômico, político e social. Em respeito aos protocolos de segurança, utilizamos plataformas remotas para a realização das entrevistas, gravadas em vídeo. Em nossos roteiros, procuramos contemplar, por exemplo, o impacto do ensino remoto na rotina dos/as estudantes e a elaboração e avaliação dos planos de combate à pandemia, no caso dos/as gestores/as públicos. Procuramos ainda estar alertas às implicações metodológicas relativas às entrevistas realizadas à distância, como discutido por Ricardo Santhiago e Valéria Magalhães (2020).

A equipe da UFRGS envolvida no projeto, composta por servidoras docentes, técnicas-administrativas e por discentes da graduação, pós-graduação e egressos/as, conduziu 56 entrevistas com estudantes de graduação com perfil de baixa renda e alguns de seus familiares. Oito delas serão analisadas neste artigo. Procurou-se garantir diversidade quanto a curso, gênero, idade, local de moradia e ingresso por diferentes categorias de cotas (além de escola pública e baixa renda, autodeclarados/as pretos, pardos ou indígenas e pessoas com deficiência). Apesar de terem seu cotidiano afetado de maneiras diversas pela pandemia, em termos gerais, os/as entrevistados/as apresentaram experiências de adesão aos protocolos de distanciamento social, avaliações críticas em relação às políticas de enfrentamento à pandemia (especialmente em nível federal), bem como valorização da pesquisa científica e da oportunidade de deixar seu relato registrado. Os casos de contágio pelo coronavírus ou de perda de familiares para a doença foram poucos. A aparente homogeneidade do grupo, no entanto, se desfaz quando atentamos para as escolhas que cada pessoa fez ao narrar e ao refletir sobre suas experiências.

As entrevistas do APERS foram conduzidas por uma servidora e um servidor da instituição. Foram entrevistados agentes públicos envolvidos na produção de dados epidemiológicos 
e socioeconômicos necessários à elaboração de políticas públicas, bem como secretários de Estado responsáveis por, com base nessas informações, implementar políticas de combate à pandemia. Até o momento, foram entrevistadas 16 pessoas, de cujos testemunhos decidimos analisar oito neste artigo. 0 governo estadual frequentemente afirma que as políticas para enfrentamento da crise sanitária e econômica estão baseadas em critérios técnicos e científicos: uma gestão pública "baseada em evidências". Assim, criou-se um "sistema de distanciamento controlado", implementado a partir de maio de 2020. 0 Rio Grande do Sul foi dividido em regiões, às quais são atribuídas "bandeiras" indicativas da gravidade da pandemia, por meio da rodagem de um sistema que leva em conta indicadores de saúde como taxa de transmissão, lotação de leitos de Unidade de Terapia Intensiva (UTI), mortalidade etc. 0 sistema foi modificado com o passar do tempo, de forma a permitir uma flexibilização das restrições de atividades econômicas.

Os/as entrevistados/as apresentaram depoimentos favoráveis ao sistema de distanciamento controlado, já que boa parte dos testemunhos veio daqueles que o formularam ou 0 aplicam no cotidiano. No entanto, havia uma contradição latente, que se procurou trazer à tona: os pesquisadores indicavam tecnicamente as "bandeiras", e, ao secretariado, cabia o poder de redefini-las, levando em conta pressões políticas de entidades de classe e governos municipais. 0 questionamento sobre a contradição entre o técnico e o político por vezes revelava-se incômodo nas entrevistas, mas, se resultou em frustração para os/as servidores/as entrevistados/as, eles/as evitaram deixar transparecer. Foram variadas as profissões de fé em relação ao valor da ciência para a definição de políticas públicas no período pandêmico e o reconhecimento da abertura do governo em relação aos/às especialistas.

\section{TESTEMUNHO E HISTÓRIA ORAL}

$\mathrm{E}$ m artigo publicado há cerca de uma década, Claudia Bacci, Alejandra Oberti e Susana Skura (2012) fazem um balanço do trabalho realizado no Archivo Oral do projeto Memoria Abierta, relacionado à ditadura argentina. 0 arquivo abriga testemunhos de "familiares de vítimas da repressão estatal, militantes, sobreviventes de centros clandestinos de detenção, presos políticos, exilados, intelectuais, artistas e profissionais, bem como integrantes de organizações políticas, sindicais, sociais e religiosas" (Bacci, Oberti e Skura, 2012:33)². 0 texto trata das ações envolvidas na produção dos testemunhos, das relações do Archivo Oral com outros projetos na Argentina e no exterior, bem como da disponibilização de seus recursos para investigadores, estudantes e educadores. É destacado o empenho para que o arquivo seja um espaço no qual "a sociedade civil encontre relatos que permitam elaborar algumas 
respostas, por precárias que elas sejam, às perguntas sobre 'como foi possível'" (Bacci, Oberti e Skura, 2012:35). A partir de fragmentos de entrevistas, as autoras analisam, entre outros tópicos, a experiência do "testemunho sobre dar testemunho". O testemunho se torna tema de reflexão "sobre quando e como é possível e faz sentido dar testemunho depois de ter vivido uma experiência que segue atemorizando" (Bacci, Oberti e Skura, 2012: 39).

Retomemos, brevemente, a noção de testemunho/a e o seu lugar na escrita da história. Referindo-se ao holocausto perpetrado pelos nazistas a suas vítimas e sobreviventes, Annette Wieviorka (2006) distinguiu:

- "o testemunho dado espontaneamente", ainda no gueto, no campo de concentração ou logo após a libertação;

- o testemunho "solicitado para fins de justiça", cuja emergência se deu a partir do julgamento de Eichmann, em 1961, quando os relatos confinados à memória familiar ganharam dimensão pública e reconhecimento social; e

- o testemunho movido "pelo imperativo social da memória", desde o final dos anos 1970, o qual foi incentivado por projetos de recolhimento massivo de relatos de sobreviventes, em um processo que transformou o holocausto em parte da cultura ocidental e em representação da "experiência absoluta".

Passou-se a cobrar dos sobreviventes que não se omitissem e honrassem seu "dever de lembrar" (Wieviorka, 2006:394). Sabemos que essas e outras reflexões sobre o testemunho foram profícuas para analisar diversas catástrofes do século XX, como as ditaduras na América Latina, nas quais também se colocaram questões sobre as particularidades do testemunho frente à justiça e na construção do conhecimento histórico (Seligmann-Silva, 2003; Sarlo, 2007).

Considerando essa história do testemunho, Wieviorka (2006: 395) alerta que os/as historiadores/as "se encontram numa situação impossível": dar conta do imperativo profissional da criticidade frente aos testemunhos, e, ao mesmo tempo, responder ao dever moral de respeito aos sobreviventes. Wieviorka se pergunta: quando confrontado com o sobrevivente, o/a historiador/a pode exercer moralmente o papel de uma memória crítica? Por meio do seu olhar, cabe ao/à historiador/a encarar as histórias de vida como construções, passíveis de crítica, portanto. Por outro lado, há o compromisso moral de reconhecer que elas são também uma espécie de armadura, de coluna vertebral da vida do sujeito que narra. Frente ao dilema, cabem duas soluções: a primeira é se distanciar dos testemunhos, nunca os colocar em questão, "abandoná-los ao esquecimento ou a outras disciplinas que não mantém o mesmo relacionamento [que a história mantém] com a verdade". A segunda solução é encará-los de maneira a não buscar neles aquilo que eles não trazem, como eventos precisos, lugares, 
datas. A riqueza dos testemunhos, para a autora, "não é a verdade factual, mas a mais sutil e, também, indispensável verdade de uma época e de uma experiência" (Wieviorka, 2006: 396).

Estamos próximos daquilo que a história oral se propõe a fazer. Basta lembrar-se dos ensinamentos de Portelli (1997: 31) a respeito do "que faz a história oral diferente": as fontes orais, entre outras coisas, "contam-nos não apenas o que o povo fez, mas o que queria fazer, o que acreditava estar fazendo e o que agora pensa que fez". Elas são fontes com uma credibilidade diferente das demais, construídas artificialmente, resultados de um projeto (e de um instante) compartilhado entre entrevistadores/as e entrevistados/as. Ainda de acordo com Portelli (1997: 35), mesmo que o pesquisador decida que haverá uma entrevista e proponha o que perguntar, são os entrevistados que decidem o que eles querem dizer. No contexto do imediatismo (Hartog, 2020) ou do atualismo (Pereira, Marques e Araújo, 2020), a história oral recupera a prática (auto)reflexiva e instaura um ritmo lento em meio à aceleração dominante.

Amparados/as em tais reflexões, exploramos os excertos das entrevistas que tratam do ato de testemunhar. Percebemos que, implícita ou explicitamente, as pessoas que entrevistamos, ao relatar o motivo pelo qual concederam seu depoimento, ou ao agregar temas ao final dele, trazem concepções de história, visões sobre o papel por elas desempenhado, a importância do registro e o significado que seu depoimento pode vir a ter. São reflexões marcadas pela vivência do processo pandêmico, reiteradas vezes percebido pelos/as entrevistados/as, de ambos grupos, como "histórico", e pelo apelo ao conhecimento científico como um saber necessário diante das mazelas atuais.

\section{TESTEMUNHANDO O TESTEMUNHO}

1 s razões dos/as estudantes para conceder a entrevista foram variadas. Marcos Kainmorador da Casa do Estudante da UFRGS, em Porto Alegre, destacou "a diversidade do perfil dos alunos que tem na universidade". Entrevistado em agosto de 2020, disse ter aceitado participar da pesquisa quando percebeu que ela valorizava essa diversidade e por considerá-la uma oportunidade para que "outros alunos, professores, docentes e técnicos também possam estar conhecendo um pouco a realidade dos estudantes indígenas". Na mesma direção, o estudante de Relações Internacionais Cam-Naté Augusto Bissindé, 26 anos de idade, da Guiné Bissau, negro, quis relatar a sua situação de estudante estrangeiro "que está também no isolamento, que mora na Casa do Estudante". Não quis apenas falar de si, mas dos "colegas estudantes africanos, não só africanos, estrangeiros que estão aqui [...]. A pessoa distanciada da familia e ainda passando por esse momento sozinha, sem ninguém, não é fácil". Cam-Naté 
chamou a atenção, na entrevista concedida em outubro de 2020, sobre como "estar longe da família, em uma sociedade diferente", com as cobranças da faculdade, pode gerar pânico e depressão. A entrevista, então, aparece como possibilidade de romper esse quadro: "juntos, a gente é mais forte. A gente vai vencer esse COVID". Nos dois casos, a entrevista é oportunidade para registro da situação de estudantes em situação de vulnerabilidade e para chamar a atenção para o fato de que eles também "fazem parte" da história a ser narrada.

Valléria Amaro de Oliveira, negra, 20 anos, estudante de Ciências Sociais, entrevistada em novembro de 2020, assim se apresentou: "eu sou uma aluna negra de periferia, vim das vilas de Porto Alegre e quero ao máximo mostrar representatividade tanto em pesquisas e entrevistas". Ao final da entrevista, optou por acrescentar uma análise sobre as mobilizações em torno de João Alberto Freitas, homem negro que foi espancado e morto por dois seguranças do supermercado Carrefour, no dia 19 de novembro de 2020, na cidade de Porto Alegre. Nesse momento, Valléria retoma o mote de sua apresentação — 0 da representatividade. Ela considera "bem importante" falar sobre racismo na pandemia, o qual "era tão evidente no dia a dia, mas essa situação que aconteceu com o Alberto na semana passada talvez abra os olhos das outras pessoas e que talvez mais pra frente quando forem assistir, perceber [...] o que negros passam todos os dias e são silenciados". Ao reforçar a necessidade de luta por justiça, ela vislumbra que "mais pra frente, daqui a cinco, dez anos, quando assistirem, talvez não tenha essa mesma dor e essa mesma situação que aconteceu". A estudante dá o testemunho em nome da vítima, mas também como parte da luta antirracista em curso, apostando que o registro e a denúncia da situação do presente ajudem a construir um futuro que não carregue "essa mesma dor". Ela vislumbra um futuro associado à transformação social.

Meise Birk, 25 anos de idade, branca, estudante de Artes Plásticas, moradora de Porto Alegre, valorizou a entrevista, realizada no início de setembro de 2020, como oportunidade para colocar para fora "muitas reflexões que ficam na cabeça só". Contou sobre o início da pandemia: "fiquei muito tempo sem conseguir desenhar, sem pintar, sem fazer nada [...]. Tudo o que eu fazia, eu odiava, nada ficava bom". A entrevista foi realizada num momento em que a estudante estava "conseguindo voltar a desenhar [...], pensando sobre muita coisa [...], tentando pensar como eu vou botar essas coisas para fora". Além de "participar da produção do conhecimento, seja qual for ele", Meise achou a entrevista "interessante para deixar documentado até para [...] poder voltar depois e refletir mais sobre esse momento". Nesse caso, o registro tem o papel autorreflexivo e de reencontro com o momento vivido por parte da "Meise do futuro". 0 desejo de "poder voltar depois" e revisitar seu relato se aproxima do manifestado, acima, por Valléria. 
A questão do registro nesse tempo único é também objeto de reflexão de luri Tinti, 25 anos, branco, estudante de Engenharia da Computação, natural do Espírito Santo, e que concedeu entrevista em novembro de 2020, da Casa do Estudante, em Porto Alegre. Em suas palavras:

eu acho importante ter documentado coisas que acontecem no dia a dia porque é algo que... é algo que é da minha curiosidade. O que acontece na nossa realidade, no nosso cotidiano, em que momento isso é registrado em papel e futuramente alguém vai ter um relato do que aconteceu antes, sabe, que não esteja só na minha memória.

Sua visão é de compartilhamento com o mundo daquilo que até então está restrito às suas recordações. Ao mesmo tempo em que luri se questiona sobre a passagem da experiência à memória e da memória à história, ele reconhece o caráter único e novo do tempo vivido. No final da entrevista, depois de narrar suas experiências pessoais, luri acrescenta:

pelo que eu sinto, a gente tá atravessando um momento histórico, assim, que vai ser contado futuramente. Mas eu acho curioso como é que a gente... ele vai chegando, vai acontecendo e a gente não se dá conta. Tem que parar, tem que conversar com o outro, ver o que está acontecendo. Pô cara, tá estranho mesmo. Tá acontecendo alguma coisa.

Para dar-se conta do que está acontecendo, então, luri vê a necessidade de "parar" e "conversar com o outro", o que acabou sendo propiciado pela experiência da entrevista de história oral.

Almiro Sagás Evaristo, 20 anos, branco, estudante de Medicina, concedeu entrevista da casa de seus pais em Governador Celso Ramos, Santa Catarina, em setembro de 2020. Sobre as razões para participar do projeto, Almiro disse: "eu concordei em participar da entrevista porque acho que a minha história é uma história de muitas pessoas". A história a que ele se referia diz respeito a "esse movimento de inserção de famílias de baixa renda" em espaços como a universidade. 0 estudante reforçou tal ideia na forma que escolheu para se apresentar no início da entrevista: "eu sou filho de um motoboy e de uma atendente de padaria e eu vou ser médico em três anos, então eu sinto que eu devo contar a minha história". No seu relato, destacou de forma positiva as políticas públicas por meio das quais ele vislumbra construir um futuro melhor. Ao final da conversa, ao ser questionado se queria acrescentar algo, 0 estudante retomou a dimensão social da sua experiência: "eu não estou falando de mim, mas eu estou falando dessas pessoas no geral, que enfrentam essas realidades que são muito peculiares e que tentam todo dia sobreviver na faculdade". Assim como Marcos, Cam-Naté e Valléria, Almiro coloca-se como representante de uma coletividade maior, que não cumpria ser esquecida nas narrativas históricas sobre a época pandêmica. Parece haver uma intenção de "fazer-se presente". 
A questão das políticas públicas também aparece na reflexão de Simone Ramos de Oliveira, ainda que no sentido de denunciar seus limites. Com 36 anos, parda, a estudante do curso de Saúde Coletiva da UFRGS foi entrevistada em setembro e outubro de 2020. Simone iniciou sua fala caracterizando o que significa viver em uma comunidade sem a mínima infraestrutura, como "saneamento básico, luz, acesso aos supermercados [...], unidade de saúde, enfim, escola". Depois de apresentar com detalhes a situação, relacionou-a ao contexto da pandemia:

As invasões, elas são mais ou menos constantes. Assim, teve um crescimento populacional bem grande, e nenhuma política pública. E daí quando a gente relaciona isso com a pandemia e com uma corrida contra o tempo, porque aqui a gente não tem água encanada do DMAE [Departamento Municipal de Águas e Esgoto], a gente tem umas caixas d'água [...]. E essas caixas d'água são cheias todos os dias, vem um caminhão pipa e enche então essas caixas d'água.

Seu relato ajuda a conhecer as "realidades muito peculiares" das pessoas que "tentam todo dia sobreviver na faculdade", como lembrou Almiro. A estudante também nos contou sobre a impossibilidade de seguir os estudos no formato remoto - por não ter acesso à internet banda larga e a computador — , sua rotina de utilização do transporte público para trabalhar, uma demissão durante a pandemia e a forma como sua vizinhança vinha respondendo às políticas de isolamento. Sobre o último ponto, ela relatou: "eu via essa parte meio vazia, sem ninguém, e daqui a pouco eu estava chegando em casa e era aquela coisa de estar todo mundo na rua, todo mundo reunido, os guris jogando bola no campinho, criança na praça e estava tudo certo". Lembra de ter ouvido falas como "aqui a gente anda com o pé no esgoto, não vai ser a COVID que vai pegar a gente". Além desse fator que ela considera cultural, a entrevistada agrega que "a gente tem um presidente que diz que não dá nada, que tudo pode". Ao conceder a entrevista, ela pretendeu garantir que realidades como a dela não fossem omitidas para os/as leitores/as do futuro. Ao mesmo tempo, denunciou o discurso do "não dá nada".

0 mesmo propósito pode ser captado na fala de Almiro. Ele contou sobre as discussões com familiares e com outras pessoas que diziam: "eu tô tomando ivermectina", e, por isso, se sentiam seguras. 0 estudante destacou "a questão da negação" e a contrapôs à ciência que, em suas palavras, "não tem todas as respostas para as coisas, por isso que ela se propõe a buscar as respostas [...]". Ele reconheceu que "é muito mais cômodo, nesse cenário, você ver o vídeo no WhatsApp que você recebeu falando que 'se você tomar vitamina tal e ivermectina você... vai ficar tudo bem [se] você pegar COVID'". Esse quadro é apresentado como "bem desapontante". Para Almiro, "não é nem tanto culpa dessas pessoas, porque as pessoas não são muito instruídas no geral, no Brasil", mas sim de mídias infodêmicas que são fonte de informação falsa, e do fato que "a gente ainda vive no país em que as pessoas escutam muito mais os seus... Os seus líderes, né, e não buscam outras fontes de informação". 
Detivemo-nos nas motivações e escolhas dos testemunhos de Almiro e Simone porque ambos tocam em questões relativas às políticas públicas, à valorização da ciência e à forma assumida pelo negacionismo, temas que têm forte presença nas entrevistas dos/as gestores/ as públicos/as, os/as quais tratam da ciência em termos mais genéricos, mas também da contribuição da História para a produção do conhecimento sobre a pandemia. A postura crítica ao negacionismo e a apologia à ciência foram essenciais na fala não apenas de técnicos envolvidos na produção de dados, que, afinal, formularam e rodam o modelo dito "baseado em evidências", mas, também, na de integrantes do secretariado. Situados em esferas mais altas da administração estadual, eles estimularam, assumiram e defenderam o modelo de distanciamento controlado, ainda que tenham, em mais de uma ocasião, cedido às pressões para flexibilização de sua aplicação.

Há um aspecto importante a se ressaltar para entender o contexto de produção das entrevistas: a maior parte dos servidores entrevistados é originária de uma fundação estadual extinta no governo anterior. A Fundação de Economia e Estatística (FEE) era responsável pela elaboração de estatísticas públicas, e, entre 2016 e 2018, os trabalhadores foram perseguidos e desvalorizados por uma postura obscurantista do governo estadual. A partir de então, foram realocados em repartições da máquina pública, sobretudo no departamento que sucedeu a Fundação. Seus empregos estavam, e ainda estão, sub judice. A partir de 2020, na administração de Eduardo Leite, no entanto, a competência de economistas, estatísticos, sociólogos etc., voltou a ser importante, agora no combate à pandemia. Portanto, a defesa do saber científico não refuta apenas o negacionismo do governo federal, mas também do governador anterior.

Iracema Keila Castelo Branco, 41 anos, branca, economista oriunda da FEE e subsecretária dos recursos humanos, ouvida em outubro de 2020, desenvolveu esse argumento pró-ciência em sua entrevista, referindo-se à atuação dos especialistas. Em suas considerações finais, lamentou que "ainda tem pessoas que não acreditam na ciência [...]. Enquanto civilização, a gente avança pela ciência", pautada em "metodologia científica validada". No testemunho de seu testemunho, a ênfase é no "que não se esqueça", no dever de lembrar que "muitas famílias perderam pessoas" que não são números. Quer dizer, no regime de historicidade presentista de Hartog (2013), manifesta-se o "dever de lembrar" de Wieviorka (2006: 394) e ele desloca-se para hoje. São pessoas, e não números; "cada um tem a sua história", representando uma "perda social". Iracema inclui nosso próprio trabalho de História Oral no bojo do conhecimento científico, ao nos parabenizar por sermos pessoas "com sensibilidade, preparadas e com conhecimento técnico" para o registro do período pandêmico.

Outros depoimentos também foram explícitos no sentido de sua importância para "a História". Ora, todos/as sabemos da ambiguidade constitutiva do nosso ofício, no qual a mes- 
ma palavra designa o discurso acerca do passado e a realidade de determinada época, ainda que os termos latinos rerum gestarum e res gestae possam ser usados para estabelecer a distinção. Em alguns relatos, como os de Fernando loannides Lopes da Cruz, 33 anos, branco, economista oriundo da FEE, responsável pelo subsídio ao governo com dados econômicos, e de Adelmir Kerschner (que prefere ser chamado de Pepo), 58 anos, branco, jornalista e responsável pela comunicação dos grupos de especialistas, os depoentes procuraram destacar o papel que suas entrevistas poderiam ter para um processo de construção do conhecimento. Suas entrevistas ocorreram, respectivamente, em julho e agosto de 2020.

Cruz afirmou saber "das dificuldades que os historiadores enfrentam para conseguir fontes", e, nesse sentido, dava-se o objetivo de sua participação na pesquisa. Ele mostrou entusiasmo diante da possibilidade de "ter uma fonte comentada, que a pessoa possa... não tenha que usar as próprias palavras, mas ouvir o que os outros têm a relatar e isso ficar registrado". Pepo usou uma imagem mais prosaica, mas nem por isso desprovida de significados: os depoimentos registrados - enfatizando a diversidade de setores sociais abarcados - seriam como uma "garrafinha, com uma cartinha, aquela história de enterrar o jornal daquele dia, sabe" que seria encontrada por alguém, "um Rodrigo da vida" — referindo-se ao nome de um de nós como exemplo de historiador/a genérico/a que poderia ter acesso no futuro a um documento testemunhal, além do "Doutor Google". Sabemos que o trabalho histórico é mais complexo do que a transmissão de informações ao longo do tempo (o/a historiador/a do futuro interrogará sua "cartinha" à luz das preocupações de sua época), mas vale registrar o anseio do entrevistado de ir além das informações que poderão ser obtidas na internet.

0 depoimento de Ana Júlia Possamai, 32 anos, branca, cientista política oriunda da FEE e coordenadora executiva do comitê de dados, entrevistada em julho de 2020, também é enfático ao valorizar as contribuições das ciências humanas para a gestão pública, particularmente em um contexto epidêmico. Ana Júlia ressalta que as "evidências" com as quais o governo implementava sua política de combate à pandemia eram produzidas por um corpo técnico altamente qualificado. 0 método científico era necessário para imprimir transparência à máquina pública e, também, para a produção de "informações pra fundamentar essa decisão [política de enfrentamento à pandemia]" e de dados que subsidiam os tomadores de decisão no sentido de "errar menos". Ela assinala que cumpre preservar vidas, pois "a gente está falando de vidas, ao fim e ao cabo". Possamai ressalta ainda a abertura do governador e da ex-secretária do Planejamento para com os dados técnicos, e tem a preocupação de enfatizar os esforços dos servidores que estão por trás da atuação estatal no combate ao processo pandêmico.

Eu tenho o viés de ser pesquisadora de uma fundação [FEE] que teve seu trabalho, seu serviço público e sua utilidade ao público extremamente questionada e colocada em perigo muitas vezes, 
e segue em perigo [...]. E que fique registrada a importância do serviço público e daqueles que se dedicam ao serviço público e daqueles que fizeram da sua vida servir ao público mesmo, do ponto de vista da pesquisa, do ponto de vista da gestão, mesmo, diretores, coordenadores, enfim.

Ana Júlia conclui parabenizando o trabalho do Arquivo Público. Aparentemente, o tom de dever para com o público abrange também nosso dever, como Arquivo, de fazer o registro. Encontramos essa noção imperativa em outros "testemunhos sobre o testemunho", como um senso de obrigação de prestar contas de sua atuação à sociedade. Isso aparece nitidamente, por exemplo, no depoimento de Ranolfo Vieira Júnior, 54 anos, branco, bacharel em Direito, delegado, vice-governador do Estado e secretário da segurança pública, entrevistado em março de 2021. Ele foi breve ao responder sobre a motivação de seu depoimento: o registro era um dever, na sua condição de

homem público, na função que eu estou hoje, eu tenho obrigação [palavra pronunciada com ênfase] de conversar com vocês e deixar aqui registrado tudo aquilo que nós fizemos, tudo aquilo que nós passamos durante esse período, e talvez isso possa ser utilizado por outras gerações no enfrentamento de situações semelhantes a esta.

Temos então a ideia de que o registro do momento atual poderia trazer ensinamentos para o porvir - uma espécie de historia magistra vitae, em que o presente assume o lugar de um passado que ensina, e o futuro o lugar de um presente que aprende.

A ex-secretária do Planejamento, orçamento e gestão, Leany Barreiro de Sousa Lemos, 50 anos, branca, cientista política, ouvida em agosto de 2020, e o atual titular da pasta, Claudio Gastal, 52 anos, branco, analista de sistemas e mestre em Sistemas de Informações, entrevistado em setembro de 2020 (portanto, antes do colapso hospitalar do início de 2021), colocam-se com mais clareza como protagonistas do momento vivido e, portanto, o registro realizado comporta a inscrição para a posteridade de seus papéis como gestores públicos. Leany Lemos, por exemplo, assinala que, em "um momento muito importante que a gente tá vivendo da humanidade", ela tinha acumulado um grande aprendizado "sobre coronavírus, sobre gestão, sobre organizações, sobre política pública, sobre transparência, sobre relações Estado-sociedade, sobre agentes políticos". Ela também expressou o desejo de, no futuro, rever-se através do depoimento e fazer o balanço dos saberes e práticas adquiridos no processo, em uma postura próxima daquela encontrada em relatos de estudantes. Claudio Gastal, por seu turno, afirmou que, embora lamentasse a tragédia vivida, não tinha queixas quanto ao fato de desempenhar um cargo público em difíceis circunstâncias:

Com a questão da COVID, eu não tenho um segundo de arrependimento [de estar ocupando uma secretaria de Estado]. Porque eu digo assim, acho que há certos momentos na História, vocês são historiadores, sabem que em momentos na História que você pode ter um papel na 
História. Um legado. Um momento. E eu muito, eu vibro aqui com a minha equipe, vibro com as coisas. Eu não tô feliz com COVID. Longe disso. Mas é poder... Estar sendo protagonista [...]. Não adianta, estou feliz, porque tá dando resultado as coisas.

Ao contrário de outros depoimentos, nessa fala, "História" não se refere a um campo de conhecimento para o qual contribuía com um depoimento, mas um processo vivido, res gestae, dotado de relevância em si, no qual considerava estar desempenhando um papel primordial e eficaz ("tá dando resultado"), pelo qual se orgulhava. Dessa forma, o projeto de História Oral poderia validar (é o que a interpelação "vocês são historiadores, sabem que..." sugere) perante as futuras gerações o lugar pelo qual gratificava-se.

\section{CONSIDERAÇÕES FINAIS}

s pessoas entrevistadas, situadas em lugares opostos da pirâmide social, coincidem
na avaliação de que vivemos um "momento histórico" digno de registro. Qualquer historiador/a haverá de concordar que todos os "momentos" são "históricos" e dignos de registro. No entanto, é evidente que estamos vivendo acontecimentos singulares, radicalmente impactantes. Não é vã a percepção de nossos/as entrevistados/as. No atual "regime de historicidade", o presente tem se imposto, com grande predominância, sobre o passado e o futuro. Isso quer dizer, como explica Hartog (2013: 149-150), que

o presente, no momento mesmo em que se faz, deseja olhar-se como histórico, como já passado. Volta-se, de algum modo, sobre si próprio, para antecipar o olhar que será dirigido para ele, quando terá passado completamente, como se quisesse "prever" o passado, se fazer passado antes mesmo de ter acontecido plenamente como presente.

Os relatos de parte de nossos entrevistados, especialmente os/as estudantes, parecem fugir a essa lógica. Além de uma perspectiva de futuro, o gesto de testemunhar aparece como uma ação possível no presente. Isso nos faz lembrar da dupla dimensão da história oral (Alberti, 2004: 33-43): ela é, ao mesmo tempo, relato e resíduo de ação. Testemunhar não é apenas relatar ação do passado, mas agir no presente. No contexto da pandemia e da onda negacionista, narrar o presente é agir sobre ele. 0 tempo epidemiológico transforma indivíduos em estatísticas. 0 caráter global da pandemia sugere uma realidade planetária comum. A profusão de informações e sua constante atualização reforçam a aceleração do tempo e a impossibilidade de parar. A história oral tenta se colocar na direção inversa dessas tendências, e, ao "oscilar entre o atual e o inatual" (Pereira, Marques e Araújo, 2020: 282), possibilita recuperar trajetórias pessoais, desvendar as condições socioeconômicas e culturais que explicam diferentes respostas à crise e, ainda, criar o espaço para a reflexão e a ação. 
Para mencionar um estudante e um gestor, retomamos a entrevista de luri Tinti e apresentamos Marco Aurélio Santos Cardoso, bacharel e mestre em economia pela Universidade Federal do Rio de Janeiro (UFRJ), 46 anos, branco, responsável pela pasta da Fazenda, com quem conversamos na antevéspera do Natal de 2020. Da mesma forma que luri, Marco Aurélio tem a percepção de que se vive um momento "histórico" a ser lembrado futuramente. "Tá acontecendo alguma coisa", segundo luri. Estamos tentando registrar essa "alguma coisa", para que não se perca em meio a tantos "choques". Aqui se recoloca o lugar do testemunho na escrita da história e o potencial da história oral para resgatá-lo e valorizá-lo em meio a uma saturação de discursos e informações; seu potencial para registrar como as experiências são vividas e interpretadas, para tornar visível o individual e o social, para transformar os números em pessoas, como disse Iracema. Foi por meio da metodologia que procuramos acessar os "testemunhos de testemunhos", e, por meio desses, encontrar sinais de concepções de História.

O fato é que, como ressaltado, as leituras envolvidas estão permeadas pelo "choque", e assim continuarão a ser, se concordarmos com Benjamin que esta é a forma de experiência característica da modernidade. As informações desencontradas que chegam evidenciam que há uma disputa de narrativas em curso. 0 discurso negacionista é atraente para ampla parcela da sociedade, e isso não se dá apenas no que toca aos fundamentos biológico-epidemiológicos da pandemia e às políticas de saúde pública para seu combate, mas também em quais relatos são admitidos como legítimos. Nessa arena, a responsabilidade do/a historiador/a é convocada ao debate público, e não cabe a omissão. Também, e sempre, nos cabe aprender com aquilo que os/as entrevistados/as nos ensinam.

Para concluir, recuperamos a sabedoria compartilhada por um estudante indígena. Laércio Gomes Mariano, 27 anos, estudante de História, da etnia Guarani, foi entrevistado em dezembro de 2020, do interior de Santa Catarina. Gostaríamos de reter da sua fala uma reflexão sobre o tempo, que dialoga com a proposta por Valléria, ao se referir àquilo que é novo, àquilo que sempre existiu, àquilo que se espera que virá a ser.

Pra nós, antes dessa pandemia, a gente já era uma aldeia, não só uma aldeia, mas várias aldeias, muito coletivas. Isso não é uma coisa nova para nós. E parece que para a sociedade de fora, isso recém surgiu. Às vezes, estão se integrando mais, tendo mais coletividade, isso parece que é algo salvador. Claro que é algo salvador, mas a gente já sabia disso faz tempo, sabe?! A gente já tem, já teve, a gente vai ter ainda nos próximos anos, para as próximas gerações. A gente vai passando isso, essa forma de coletividade, essa forma de generosidade que a gente já cultiva há milhares de anos. Então, acho que, quanto ao futuro, eu só tenho a dizer isso, que a gente vai continuar assim e nada vai mudar a gente. 
As concepções aqui apresentadas sobre um tempo histórico excepcional sobrevivem à leitura de outras historicidades, que se situam em um passado e um futuro coletivamente partilhados? 0 desafio de Hartog, de inscrever a ordem temporal pandêmica no coletivo, não se coloca ao estudante indígena: já está dada em seu tempo de "muito antes". Ao que nos parece, a perspectiva "presentista" encontra-se mais assentada entre gestores públicos do que entre estudantes, que dão credibilidade à possibilidade de um futuro melhor com base na ação do presente e nas lições trazidas pelo passado. Ora, conforme vimos, entre diversos/as gestores/as (o exemplo do vice-governador é o mais marcante) é esse presente - do qual se percebem como protagonistas — que pode ensinar o futuro. Para eles, as entrevistas tiveram menos um caráter de interrupção em um tempo acelerado, e mais de um compromisso adicional, mais ou menos importante, em agendas contínuas, prementes.

No entanto, de acordo com Turin (s.d.: 7), na incessante aceleração do tempo, "quanto mais avançamos, mais perdemos o tempo para evitar o fim". Em um momento reconhecido pelos/as entrevistados/as como de fratura, compreender o que entendem por tempo histórico é importante para nossos esforços de registro e intervenção crítica em uma realidade social traumática. Enfrentemos o espanto de Stuart Hall e deixemos ao espaço de entrevista o oferecimento do intervalo para que as pessoas com quem conversamos "contem uma história", como estimula Ailton Krenak. Em meio ao turbilhão — pandêmico, infodêmico, presentista, atualista — , o tempo da entrevista reserva um momento ímpar de autorreflexão e desaceleração — inclusive para nós, entrevistadores/as. No compartilhamento de suas experiências, os/as entrevistados/as (re)encontram-se com quem são, com quem foram, com quem pensam que serão, avaliando um presente de horror, evidenciando suas concepções de historicidade e fugindo, ainda que momentaneamente, à avalanche informacional do tempo vivido. Quiçá a História Oral possa ajudar a adiar o fim do mundo.

Conflitos de interesse: nada a declarar.

Fonte de financiamento: nenhuma.

Contribuições dos autores: RODEGHERO, C. S.: Administração do Projeto, Realização de Entrevistas, Análise Formal, Conceituação, Escrita - Primeira Redação, Escrita - Revisão e Edição; WEIMER, R. de A.: Administração do Projeto, Realização de Entrevistas, Análise Formal, Conceituação, Escrita - Primeira Redação, Escrita - Revisão e Edição. 


\section{NOTAS}

1 Para maiores informações, ver: https://www.apers.rs.gov.br/documentando-covid19-rs; www.ufrgs.br/repho/projetos/. Acesso em: 20 jul. 2021.

2 Textos de outros idiomas são de tradução livre.

\section{ENTREVISTAS}

BIRK, Meise. Entrevista cedida a Juliana Carolina da Silva e a Regina Célia Lima Xavier. Porto Alegre: 3 set. 2020.

BISSINDÉ, Cam-Naté Augusto. Entrevista cedida a José Augusto Zorzi e a Marina Widholzer da Silva. Porto Alegre: 23 out. 2020.

BRANCO, Iracema Keila Castelo. Entrevista cedida a Rodrigo de Azevedo Weimer. Porto Alegre: 20 out. 2020.

CARDOSO, Marco Aurélio Santos. Entrevista cedida a Clarissa Sommer Alves e a Rodrigo de Azevedo Weimer. Porto Alegre: 23 dez. 2020.

CRUZ, Fernando loannides Lopes da. Entrevista cedida a Clarissa Sommer Alves e a Rodrigo de Azevedo Weimer. Porto Alegre: 25 jul. 2020.

EVARISTO, Almiro Sagás. Entrevista cedida a Carla Simone Rodeghero e a Morgan Lemes Santos. Porto Alegre: 18 set. 2020.

GASTAL, Claudio Leite. Entrevista cedida a Clarissa Sommer Alves. Porto Alegre: 25 set. 2020.

KAINGANG, Marcos. Entrevista cedida a Carla Simone Rodeghero e a Manuela Perondi Pavoni. Porto Alegre: 18 ago. 2020.

KERSCHNER, Aldemir Lauri (Pepo). Entrevista cedida a Clarissa Sommer Alves e a Rodrigo de Azevedo Weimer. Porto Alegre: 13 ago. 2020.

LEMOS, Leany Barreiro de Sousa. Entrevista cedida a Clarissa Sommer Alves e a Rodrigo de Azevedo Weimer. Porto Alegre: 20 ago. 2020.

MARIANO, Laércio Gomes. Entrevista cedida a Eduarda Borges da Silva e a Manuela Perondi Pavoni. Porto Alegre: 10 dez. 2020.

OLIVEIRA, Simone Ramos de. Entrevista cedida a Carla Simone Rodeghero e a Marina da Silva Widholzer. Porto Alegre: 28 set. 2020 e 7 out. 2020.

OLIVEIRA, Valléria Amaro de. Entrevista cedida a Manuela Perondi Pavoni e a Marina da Silva Widholzer. Porto Alegre: 26 nov. 2020.

POSSAMAI, Ana Júlia. Entrevista cedida a Rodrigo de Azevedo Weimer. Porto Alegre: 31 jul. 2020.

TINTI, luri. Entrevista cedida a Carla Simone Rodeghero e a Morgan Lemes Santos. Porto Alegre: 19 nov. 2020.

VIEIRA JÚNIOR, Ranolfo. Entrevista cedida a Clarissa Sommer Alves e a Rodrigo de Azevedo Weimer. Porto Alegre: 17 mar. 2021. 


\section{REFERÊNCIAS BIBLIOGRÁFICAS}

ALBERTI, V. Ouvir contar: textos em história oral. Rio de Janeiro: FGV, 2004.

ARAÚJO, V.; PEREIRA, M. Atualismo 1.0: como a ideia de atualização mudou o século XXI. 2. ed. Vitória: Mariana: Editora Milfontes; SBTHH, 2019.

BACCI, C.; OBERTI, A.; SKURA, S. Testimonios en archivos: nuevas perspectivas. História Oral, v. 15, n. 2, p. 33-49, jul.-dez. 2012.https://doi.org/10.51880/ho.v15i2.257.

BENJAMIN, W. Baudelaire e a modernidade. Belo Horizonte: Autêntica, 2015.

HALL, S. Da diáspora: identidades e mediações culturais. Belo Horizonte: Editora da UFMG, 2003.

HARTOG, F. Regimes de historicidade: presentismo e experiências do tempo. Belo Horizonte: Autêntica, 2013.

HARTOG, F. A COVID-19 e as perturbações do presentismo. ArtCultura, Uberlândia, v. 22, n. 41, p. 50-56, jul.-dez. 2020.https://doi.org/10.14393/artc-v22-n41-2020-58640.

HOBSBAWM, E. A era dos extremos: o breve século XX - 1914-1991. São Paulo: Companhia das Letras, 1996.

KRENAK, A. Ideias para adiar o fim do mundo. Rio de Janeiro: Companhia das Letras, 2019.

PEREIRA, M.; MARQUES, M.; ARAÚJO, V. Almanaque da COVID-19: 150 dias para não esquecer ou a história do encontro entre um presidente fake e um vírus real. Vitória: Editora Milfontes, 2020.

PORTELLI, A. O que faz a história oral diferente? Projeto História, São Paulo, n. 14, p. 25-39, 1997.

PORTELLI, A. História oral como arte da escuta. São Paulo: Letra e Voz, 2016.

SANTHIAGO, R.; MAGALHÃES, V. B. Rompendo o isolamento: reflexões sobre história oral e entrevistas à distância. Anos 90, Porto Alegre, v. 27, p. 1-18, 2020. https://doi.org/10.22456/1983-201X.102266.

SARLO, B. Tempo passado: cultura da memória e guinada subjetiva. São Paulo: Belo Horizonte: Companhia das Letras; UFMG, 2007.

SELIGMANN-SILVA, M. História, memória, literatura: o testemunho na era das catástrofes. Campinas: Editora da UNICAMP, 2003.

SHAH, H. COVID-19 recovery: science isn't enough to save us. Nature, London, v. 591, Mar.25, 2021. https:// doi.org/10.1038/d41586-021-00731-7.

TURIN, R. Tempos pandêmicos e cronopolíticas. São Paulo: N-1 edições, s.d.

VIDAL-NAQUET, P. Os assassinos da memória: "um Eichmann de papel" e outros ensaios sobre o revisionismo. Campinas: Papirus, 1988.

WIEVIORKA, A. The witness in history. Poetics Today, Durham, v. 27, n. 2, p. 385-397, 2006. https://doi. org/10.1215/03335372-2005-009. 